University of Nebraska - Lincoln

DigitalCommons@University of Nebraska - Lincoln

2010

Current US Military Operations and Implications for Military

Surgical Training

Joshua A. Tyler

Brooke Army Medical Center, Josh.Tyler@amedd.army.mil

Kevin S. Clive

Brooke Army Medical Center

Christopher E. White

U.S. Army Institute of Surgical Research

Alec C. Beekley

Madigan Army Medical Center

Lorne H. Blackbourne

U.S. Army Institute of Surgical Research

Follow this and additional works at: https://digitalcommons.unl.edu/usarmyresearch

Part of the Operations Research, Systems Engineering and Industrial Engineering Commons

Tyler, Joshua A.; Clive, Kevin S.; White, Christopher E.; Beekley, Alec C.; and Blackbourne, Lorne H., "Current US Military Operations and Implications for Military Surgical Training" (2010). US Army Research. 155.

https://digitalcommons.unl.edu/usarmyresearch/155

This Article is brought to you for free and open access by the U.S. Department of Defense at DigitalCommons@University of Nebraska - Lincoln. It has been accepted for inclusion in US Army Research by an authorized administrator of DigitalCommons@University of Nebraska - Lincoln. 


\title{
Current US Military Operations and Implications for Military Surgical Training
}

\author{
Joshua A Tyler, MD, Kevin S Clive, MD, Christopher E White, MD, FACS, Alec C Beekley, MD, FACS, \\ Lorne H Blackbourne, MD, FACS
}

BACKGROUND: Since 2001, US military surgeons have deployed frequently, with many surgeons deploying within 1 year of graduating residency. The purpose of this study was to evaluate readiness of recent graduates to manage combat-related injuries and to make recommendations for improvements in training military surgeons.

STUDY DESIGN: We reviewed casualties treated at the $31^{\text {st }}$ Combat Support Hospital in Baghdad from December 2003 to November 2004. We identified 3,426 wounded patients; of these, 2,648 (77.3\%) required an operative procedure. There were 2,788 patients $(81.4 \%)$ who sustained penetrating injuries. The most common procedures performed were debridement of wounds (39\%), skeletal fixation (14.7\%), and exploratory laparotomy (11.4\%). Common procedures were compared with 15 case logs from the ACGME database for our institution from 2005 to 2009.

RESULTS: $\quad$ Graduating residents averaged 973 cases during residency (range 867 to 1,293, median 921). This included experience with most procedures encountered except nephrectomy (1.5 procedures per resident [PPR]), craniotomy (1.1 PPRs), inferior vena cava injury (1.1 PPRs), bladder repair (0.87 PPR), and duodenal injury (0.6 PPR). Residents had minimal experience with skeletal fixation and external genital trauma.

CONCLUSIONS: Recent surgical residency graduates are prepared for deployment in support of US military operations for the majority of injuries encountered. However, familiarization with procedures that fall outside the traditional general surgical curriculum would improve their ability to treat these injuries. To enhance experience with rare injuries, cadaver studies and animal models may serve as training tools before deployment. (J Am Coll Surg 2010;211:658-662. () 2010 by the American College of Surgeons)

Since the initiation of combat operations in Afghanistan in Operation Enduring Freedom in 2001, US military surgeons have deployed frequently. Currently, general surgeons who serve in the US military are trained either in civilian institutions or military training programs, which

Disclosure information: Nothing to disclose.

Disclaimer: The opinions or assertions contained herein are the private views of the authors and are not to be construed as official or reflecting the views of the Department of the Army, Department of Defense, or the US Government. This work was prepared as part of their official duties and, as such, there is no copyright to be transferred.

Abstract presented at the American College of Surgeons 96th Annual Clinical Congress, Surgical Forum, Washington, DC, October 2010.

Received June 11, 2010; Revised July 15, 2010; Accepted July 15, 2010. From the Department of General Surgery (Tyler, Clive), Brooke Army Medical Center, and the US Army Institute of Surgical Research (White, Blackbourne), Fort Sam Houston, TX, and the Department of General Surgery, Madigan Army Medical Center, Tacoma, WA (Beekley).

Correspondence address: Joshua A Tyler, MD, Capt, USAF, MC, Department of General Surgery, Brooke Army Medical Center, 3851 Roger Brooke Dr MCHE-SDG, Fort Sam Houston, TX 78234. email: Josh.Tyler@ amedd.army.mil are closely affiliated with civilian institutions. Regardless of residency training program type, all military general surgeons complete their trauma training on civilian trauma patients. Most graduating military general surgeons will deploy within 1 year of completing residency training, and will encounter combat injuries from mechanisms that are substantially different than those seen in civilian trauma. ${ }^{1}$ The current conflict has resulted in a high incidence of explosion-related injuries due to the frequent use of improvised explosive devices by enemy combatants. This has resulted in a large proportion of extremity trauma. ${ }^{2,3}$ Some have theorized that extremity trauma is more common in this engagement than in earlier wars due to the body armor currently worn by US soldiers, which offers more protection to the torso and abdomen than extremities. Although numerous descriptive studies to date have described operative caseload and injury patterns seen in both Iraq and Afghanistan, only a single study has compared in-theater surgical cases with caseloads completed by graduating chief surgical residents. ${ }^{4}$ The purpose of this study was to evaluate the readiness of recent surgical residency graduates to 


\section{Abbreviations and Acronyms}

$\mathrm{CSH}=$ combat support hospital

$\mathrm{PPR}=$ procedures per resident

$\mathrm{X}$-lap $=$ exploratory laparotomy

manage the types of injuries seen in the deployed setting and to make recommendations for improvements in training military surgeons.

\section{METHODS}

To compare the caseload of the deployed general surgeon to cases encountered in residency by graduating military general surgical residents, we compared the $31^{\text {st }}$ Combat Support Hospital (CSH) database with ACGME case logs for graduating chief surgical residents from a single military training program. The $31^{\text {st }} \mathrm{CSH}$ database used the detailed experience of a single Role III military treatment facility from December 2003 to November 2004. A Role III (formerly level III) military treatment facility in the deployed environment is equivalent to a level I trauma center in the United States, with availability of multiple specialties to include general surgery, orthopaedics, vascular surgery, neurosurgery, facial surgery, ophthalmology, and cardiothoracic surgery. During this time, the CSH was located both in the International Zone in Baghdad as well as in Balad and had received casualties since shortly after the liberation of Iraq. This time frame also included the offensive to recapture the city of Fallujah in November 2004, which resulted in a spike in casualties. Cases were analyzed by surgical specialty completing the case (eg, general surgery, vascular, orthopaedics, etc), and cases completed by a general surgeon were further broken down by case type and specific anatomic injury encountered. These cases were compared with ACGME case logs for 5 years of chief residents $(n=15)$ from the general surgery training program at Brooke Army Medical Center from graduation years 2005 to 2009.

\section{RESULTS}

During the study period of December 2003 to November 2004, 3,426 combat-wounded patients were identified. Of these, 2,648 patients $(77.3 \%)$ required an operative procedure and 1,134 patients $(42.8 \%)$ required more than 1 procedure at initial operation. There were 2,788 patients $(81.4 \%)$ who sustained penetrating injuries, and $18.6 \%$ of injuries encountered were due to blunt trauma. Penetrating injuries were much more common than in the US civilian trauma setting $(81.4 \%$ vs $10.1 \%, \mathrm{p}<0.001) .{ }^{5}$ Common general surgical procedures are shown in Table 1 . The mid-
Table 1. General Surgical Procedures by Type

\begin{tabular}{lcc}
\hline Procedure & $\begin{array}{c}\text { Frequency } \\
\text { (\% of overall } \\
\text { cases) }\end{array}$ & $\begin{array}{c}\text { Resident experience } \\
\text { (procedures per } \\
\text { resident) }\end{array}$ \\
\hline Irrigation and debridement & 56.3 & $\mathrm{NR}$ \\
\hline Exploratory laparotomy & 16.7 & 22.8 \\
\hline Soft tissue repair & 8.7 & $\mathrm{NR}$ \\
\hline Vascular exploration & 7.4 & 6.8 \\
\hline Amputation & 5.4 & 6.33 \\
\hline Neck exploration & 3.1 & 3.6 \\
\hline Thoracotomy & 2.4 & 6.93 \\
\hline
\end{tabular}

NR, procedure frequency not captured by ACGME case log database.

dle column displays the percentage of overall general surgical procedures in the deployed setting, and the right column displays mean number of cases completed per resident during the course of their general surgical training (PPR, procedures per resident). The most common surgical procedures performed (by any specialty) were irrigation and debridement of wounds (39\%), followed by skeletal fixation (14.7\%) and exploratory laparotomy (X-lap) (11.4\%). At exploratory laparotomy, bowel repair/resection was the most common procedure performed (42\%), followed by retroperitoneal hematoma exploration (15.4\%), splenectomy $(12.8 \%)$, and control of hemorrhage from liver injury $(10.8 \%)$. Diaphragmatic and gastric injuries were also common $(9.5 \%$ and $9.3 \%$, respectively). Complete details of the commonly performed procedures at X-lap are described in Table 2. Major vascular procedures comprised $5.4 \%$ of total procedures (211 of 4,058), with the most commonly injured vessels being the femoral vessels $(24.6 \%)$, the brachial vessels $(18.5 \%)$, popliteal vessels $(10.9 \%)$, and iliac vessels (10.4\%), respectively. These procedures were then compared with 15 chief resident case logs from the ACGME case log database from our institution. Graduating chief residents did an average of 973 cases during their residency (range 867 to 1,293, median 921). Residents did an average of $23 \mathrm{X}$-laps and 7 thoracotomies, as well as a large number of bowel resection or repairs (mean 80.1 PPRs), open cholecystectomies (10.9 PPRs), and gastrotomy repairs (5.6 PPRs). Residents completed nearly 7 (mean 6.8) vascular explorations in the setting of trauma for major vascular injury. Residents completed on average at least 2 of each of the other procedures encountered except nephrectomy (1.5 PPRs), craniotomy (1.1 PPRs), IVC injury (1.1 PPRs), bladder repair (0.87 PPR), and duodenal injury (0.6 PPR). Residents had minimal experience with skeletal fixation and external genital trauma. The ACGME case log did not capture resident experience with retroperitoneal hematoma exploration, treatment of rectal injury, irrigation and debridement of soft tissue wounds, and diaphragm repair. 
Table 2. Procedures Performed at Exploratory Laparotomy

\begin{tabular}{lcc}
\hline Procedure & $\begin{array}{c}\text { Frequency } \\
\text { (\% of all } \\
\text { X-laps) }\end{array}$ & $\begin{array}{c}\text { Resident experience } \\
\text { (procedures } \\
\text { per resident) }\end{array}$ \\
\hline Bowel repair/resection & 42 & 80.1 \\
\hline $\begin{array}{l}\text { Negative/procedure not } \\
\text { described }\end{array}$ & 30.5 & 22.8 \\
\hline $\begin{array}{l}\text { Retroperitoneal hematoma } \\
\text { exploration }\end{array}$ & 15.4 & $\mathrm{NR}$ \\
\hline Splenectomy & 12.8 & 4.8 \\
\hline Liver hemostasis & 10.8 & 1.9 \\
\hline Diaphragm repair & 9.5 & $\mathrm{NR}$ \\
\hline Gastrotomy repair & 9.3 & 5.6 \\
\hline Rectal wound & 7.8 & $\mathrm{NR}$ \\
\hline Bladder repair & 5.2 & 0.87 \\
\hline Colostomy & 4.3 & 3.7 \\
\hline Mesenteric vascular injury & 3.5 & $\mathrm{NR}$ \\
\hline Nephrectomy & 3.5 & 1.5 \\
\hline Pancreatic drainage & 2.8 & 1.9 \\
\hline IVC injury & 2.4 & 1.1 \\
\hline Duodenal injury & 2.2 & 0.6 \\
\hline NR procedre freguncy & & \\
\hline
\end{tabular}

NR, procedure frequency not captured by ACGME case log database; X-lap, exploratory laparotomy.

\section{DISCUSSION}

This study compared surgical caseloads of military surgeons in the deployed setting with cases completed by military surgical residents in order to better identify injuries and procedures where limited or minimal experience could be augmented with curriculum modification. Although residents are prepared to encounter the majority of injuries seen in the deployed setting, limited resident experience was seen with numerous injuries including nephrectomy, craniotomy, IVC injury, duodenal injury, and bladder repair. Residents had minimal experience with external fixation of skeletal injury and external genital trauma. In addition, further areas of resident experience could not be assessed due to limitation of the ACGME case log, which fails to capture resident experience with diaphragm repair, identification and treatment of rectal injury, and retroperitoneal hematoma exploration. There are multiple possible explanations for the resident experience gap with certain injuries. First, as expected, residents had limited experience with rare injuries to include IVC, duodenal, and pancreatic injuries. Additionally, residents training in robust graduate medical education-training platforms with rapid availability of other specialties may have limited exposure to procedures that fall under the domain of those specialties. Examples include genitourinary trauma, intracranial pathology, and skeletal extremity trauma. However, these injuries and procedures may fall under the purview of the deployed general surgeon, and procedural familiarity before deployment would be optimal.
To our knowledge, other than a single poster at the American College of Surgeons meeting, ${ }^{4}$ this study represents the only comparison of operative cases seen in the current theater of combat operations to cases completed by military surgical residents. It is also the first manuscript to be published on the topic specifically regarding the US military experience. This topic has additionally been considered by military surgeons from the United Kingdom, who have detailed their experience in both Iraq and Afghanistan and made recommendations for training curriculum modification ${ }^{6}$ and implemented new strategies for training military surgeons such as deployment of surgical registrars to the theater of operations. ${ }^{7}$

As stated by Hippocrates and echoed by prominent surgeons since, "If one wants to learn surgery, one must go to war." The history of trauma surgery has developed in parallel with the history of armed conflict. Prominent surgeons throughout history have included many who gained distinction through their military service: Pare, Larrey, Letterman, Bethune, and even DeBakey. Although many surgeons have learned surgery and gained great operative skill in the management of combat wounded, the modern era of predeployment surgical education began with the first appearance of the topic in the modern literature in 1990 with the publication of an article by Rignault, a French general and surgeon, in Military Medicine. ${ }^{8}$ In his article, General Rignault advocated the rotation of military surgeons in busy civilian trauma centers for 3 to 6 months at a time in order to immerse the surgeon in the care of the trauma patient. In addition, he advocated that military surgical training be a dynamic model, with analysis of caseloads encountered in current military operations, accompanied by training curriculum modification to reflect deployed injury patterns.

Immediately after the publication of General Rignault's paper, Operation Desert Storm occurred, after which numerous reports of suboptimal combat casualty care were published by the Government Accountability Office. ${ }^{9-13}$ This prompted numerous developments in predeployment surgical education tailored to staff surgeons, including revision to the Emergency War Surgery (EWS) course, the Army Trauma Training Center (ATTC), the Air Force Center for Sustainment of Trauma and Readiness Skills (C-STARS), emphasis on Advanced Trauma Life Support (ATLS) algorithms for deployed medical personnel, Tactical Combat Casualty Care (TCCC), increasing use of surgical simulation, and the Combat Casualty Care Course (C4) for incoming military physicians. All of these predeployment training platforms represent significant contributions to improving the care of the combat wounded 
patient, but many are for all medical providers (physicians, nurses, and medics), and few are surgeon-specific.

There are currently no resident-focused, surgeon-specific, combat trauma training courses. Despite this limitation, many have recognized the need for increased trauma training courses in the era of nonoperative trauma management. The courses include American College of Surgeons-affiliated courses such as Advanced Trauma Operative Management (ATOM), a widely-used porcine-injury trauma model, and Advanced Surgical Skills in the Exposure of Trauma (ASSET), a cadaveric exposure course currently in the final stages of development. Both the Advanced Trauma Operative Management and cadaveric exposure courses such as Advanced Surgical Skills in the Exposure of Trauma and the Trauma Exposure Course (TEC), described by Gunst and colleagues ${ }^{14}$ in 2009 , have been incorporated into general surgical training programs and shown to be advantageous in surgical education using both self-efficacy assessment instruments and objective measures such as written tests. ${ }^{14-17}$ Although many general surgical training programs currently use porcine or cadaveric injury models, no standardized curriculum or organized military resident training program exists.

To augment limited resident experience with rare injuries and injuries seen outside the standard general surgery training curriculum, we developed a 2-day course specifically for military surgical chief residents, incorporating the benefits of both porcine injury models and cadaveric exposure courses. The course will additionally include militaryspecific training such as damage control orthopaedics and neurosurgery for the deployed general surgeon, and a review of the Joint Theater Trauma System (JTTS) Clinical Practice Guidelines (CPGs). ${ }^{18}$ Although this course was developed for military chief surgical residents based on the data presented within our article, it would also provide an evidence-based predeployment training platform for reserve and active duty surgeons with limited deployment experience, or alternatively, a time lapse since their last deployment with possible trauma skill atrophy. Currency remains an issue for active duty and reserve component military surgeons because many will go for significant lengths of time between deployments and are not exposed to surgical trauma management in their clinical positions within general surgery and associated general surgical subspecialties. For the active duty surgical oncologist or minimally invasive surgeon, a surgical practice in the continental US may have very limited trauma exposure. However, regardless of subspecialty, the deployed general surgeon must be well versed in management of traumatic injury. To enhance trauma skill retention and currency, regular recertification in our course, in addition to the already discussed rotations at busy level I trauma centers such as the Air Force Center for Sustainment of Trauma and Readiness Skills and the Army Trauma Training Center may add to trauma skill retention.

This study has the following limitations: The $31^{\text {st }} \mathrm{CSH}$ database, while providing a beneficial account of patient injury patterns and surgical procedures, did not always account for which specialty completed the procedure that might typically be performed by numerous specialties (eg, fasciotomies, amputation, or debridement of soft tissue wounds). In addition, case categories were predefined and broad, and experience in the care of the burn patient, an important competency of the military surgeon, was not specifically captured by the database. A single database was used as a representative cohort of injuries encountered in the deployed setting, representing a snapshot of the injuries seen at a certain time in the war, which is highly dependent on the intensity of current combat operations. This occurred at a Role (formerly level) III hospital during a period of near continuous combat operations against the growing insurgency in Iraq. Experience at a Role (level) II facility may have a slight variation in the types and volumes of procedures performed due to inherent differences seen at various levels of care of the wounded soldier. Furthermore, as the engagements in Iraq and Afghanistan evolved over time, the injury patterns sustained by casualties changed as a result of an increased use and sophistication of improvised explosive devices and other munitions as the enemy became more experienced in engaging US troops. ${ }^{1}$

Limitations also existed with the resident cohort. Residents assessed were from a single military general surgical training program at Brooke Army Medical Center, a level I trauma center. Variations in military surgical training programs currently exist, with Army programs more likely to be independent with some rotations at outside facilities; Air Force programs are all generally affiliated with large university medical centers. This disparity might cause a discrepancy in the case averages reported. Although no residents from Air Force or Navy programs were included in the resident cohort of this study, the poster by JP Fox and colleagues $^{4}$ from the American College of Surgeons Clinical Congress in 2008, which compared experience of a cohort of graduating chief residents from an integrated Air Force program with cases seen at Balad Air Base in Iraq, identified similar findings of limited resident experience with rare injuries and those that fall outside traditional general surgery curriculum. A future study on this topic might incorporate surgical resident experience at Army, Navy, and Air Force training programs.

Additionally, resident experience was assessed using the objective measure of case quantity according to the 
ACGME case log. This is currently the gold standard to assess resident experience, but it fails to quantify the more subjective measure of sound surgical decision making-a critical component of the timely and effective care of the badly wounded trauma patient. Finally, resident experience, as indicated by the ACGME case log, may not be a true reflection of resident operative experience given ACGME case-reporting rules during the study period limiting resident surgeons to counting only 1 procedure of a given operation, even in cases where more than 1 procedure may have been completed. This limitation has been recognized, prompting recent changes to the ACGME case log reporting requirements.

In summary, recent surgical residency graduates are prepared for deployment in support of US military combat operations for the majority of injuries they will encounter. However, familiarization with procedures that fall outside the traditional general surgical curriculum (skeletal fixation, genitourinary trauma, and craniotomy) will enhance their ability to treat these injuries. To enhance experience with rare injuries (IVC, major vascular, duodenal), cadaver studies, animal models, and computer simulations could serve as training tools before deployment.

\section{Author Contributions}

Study conception and design: Tyler, Blackbourne Acquisition of data: Beekley, Blackbourne Analysis and interpretation of data: Tyler, Clive [Drafting of manuscript: Tyler, Beekley, White Critical revision: Tyler, Beekley, White, Blackbourne

\section{REFERENCES}

1. Kelly JF, Ritenour AE, McLaughlin DF, et al. Injury severity and causes of death from Operation Iraqi Freedom and Operation Enduring Freedom: 2003-2004 versus 2006. J Trauma 2008; 64(2 Suppl):S21-S27.

2. Holcomb JB, McMullin NR,Pearse L, et al. Causes of death in US Special Operations Forces in the global war on terrorism: 2001-2004. Ann Surg 2007;245:986-991.
3. Owens BD, Kragh JF Jr, Macaitis J, et al. Characterization of extremity wounds in Operation Iraqi Freedom and Operation Enduring Freedom. J Orthop Trauma 2007;21:254-257.

4. Fox JP, Tyler JA, Paulick J, et al. Iraq, integrated programs, and training military surgeons. Presented at American College of Surgeons 2008 Clinical Congress, San Francisco, CA. October 2008.

5. NTDB Annual Report 2009. Available at: http://www.facs.org/ trauma/ntdb/ntdbannualreport2009.pdf. Accessed May 29, 2010.

6. Ramasamy A, Hinsley DE, Edwards DS, et al. Skill sets and competencies for the modern military surgeon: lessons from U.K. military operations in Southern Afghanistan. Injury 2010; 41:453-459.

7. Brooks AJ, Ramasamy A, Hinsley D, Midwinter M. Military general surgical training opportunities on operations in Afghanistan. Ann R Coll Surg Engl 2009;91:417-419.

8. Rignault DP. How to train war surgery specialists: Part II. Mil Med 1990;155:143-147.

9. Operation Desert Storm: Full Army Medical Capability Not Achieved. Washington, DC: US General Accounting Office; August 1992. GAO/NSIAD-92-175.

10. Operation Desert Storm: Improvements Required in the Navy's Wartime Medical Care Program. Washington, DC: US General Accounting Office; July 1993. GAO/NSIAD-93-189.

11. Operation Desert Storm: Problems with Air Force Medical Readiness. Washington, DC: US General Accounting Office; December 1993. GAO/NSIAD-94-58.

12. War Time Medical Care: DOD Is Addressing Capability Shortfalls, but Challenges Remain. Washington, DC: US General Accounting Office; September 1996. GAO/NSIAD-96-224.

13. War Time Medical Care: Personnel Requirements Still Not Resolved. Washington, DC: US General Accounting Office; June 1996. GAO/NSIAD-96-173.

14. Gunst M, O'Keeffe T, Hollett L, et al. Trauma operative skills in the era of nonoperative management: the trauma exposure course (TEC). J Trauma 2009;67:1091-1096.

15. Ali J, Ahmed N, Jacobs LM, Luk SS. The Advanced Trauma Operative Management course in a Canadian residency program. Can J Surg 2008;51:185-189.

16. Jacobs LM, Burns KJ, Luk SS, Marshall WT 3rd. Follow-up survey of participants attending the Advanced Trauma Operative Management (ATOM) Course. J Trauma 2005;58:1140-1143.

17. Jacobs LM, Burns KJ, Kaban JM, et al. Development and evaluation of the advanced trauma operative management course. J Trauma 2003;55:471-479

18. US Army Institute of Surgical Research. Joint Theater Trauma System Clinical Practice Guidelines. Available at: http://www. usaisr.amedd.army.mil/cpgs.html. Accessed August 2, 2010. 